\title{
Bifilm defects and porosity in Al cast alloys
}

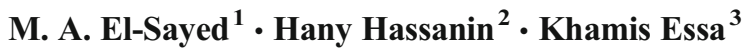

Received: 4 September 2015 / Accepted: 14 December 2015 / Published online: 5 January 2016

(C) The Author(s) 2016. This article is published with open access at Springerlink.com

\begin{abstract}
Liquid $\mathrm{Al}$ and $\mathrm{Mg}$-base alloys are so reactive that it is reasonable to assume that the surface layer is always oxidized. If liquid aluminium entered a mould cavity with a velocity greater than a critical value, the surface skin of the liquid metal would fold over onto itself and be submerged into the bulk liquid with a volume of air entrapped within it, creating what is called a bifilm defect. This defect not only acts as a crack but also it is recognized to initiate hydrogen porosity in the solidified casting, which has been found to have detrimental effects on the tensile and fatigue properties of the castings produced. Previous research suggested that during solidification, the hydrogen, in excess of the solubility limit, comes out of the solution and diffuses into the bifilm gap, expanding it into a pore. Also, placing liquid metal in a vacuum may cause its entrained bifilms to expand, enhancing their buoyancy and therefore their floatation to the surface of the melt. In this work, a casting from an A356 Al alloy was allowed to solidify under vacuum. The solidified casting was sectioned into two halves, and the internal surfaces of the pores were investigated
\end{abstract}

Khamis Essa

k.e.a.essa@bham.ac.uk

M. A. El-Sayed

m_elsayed@aast.edu

Hany Hassanin

h.hassanin@kingston.ac.uk

1 Department of Industrial and Management Engineering, Arab Academy for Science and Technology and Maritime Transport, PO Box 1029, Abu Qir, Alexandria 21599, Egypt

2 School of Mechanical and Automotive Engineering, Kingston University, London, UK

3 School of Mechanical Engineering, University of Birmingham, Birmingham, UK using an SEM to determine their relationship with double oxide film defects.

Keywords Entrained inclusions · Aluminium casting · Porosity $\cdot$ Hydrogen

\section{Introduction}

The transfer of liquid $\mathrm{Al}$ alloys and the action of pouring into a mould are often accompanied by entrainment of the oxidized surface skin of the alloy. The very high reactivity of liquid $\mathrm{Al}$ with oxygen in the air means that the surface of the liquid metal can be considered to be permanently coated with an oxide layer. Therefore, as such layer is ruptured by movement of the liquid metal underneath, the rupture must be almost instantaneously sealed by the reaction between the $\mathrm{Al}$ and oxygen. Pouring or transfer of the liquid metal results in considerable splashing of the liquid metal (which has a viscosity similar to that of water), and as the splashes coalesce and merge with the bulk liquid, a doubled-over oxide film "a bifilm" can be carried into the liquid metal. The sides of the bifilm defect are unbonded and would capture a portion of the local atmosphere to be carried into the melt, from where it may be swept into the mould cavity (see Fig. 1) [1].

Bifilm defects therefore consist of a crevice in the solid metal, formed by the unbonded oxide films, and contained a layer of gas. They form a defect in the final solidified casting of variable size, and with variable orientation with respect to any applied load experienced by the casting in service. It is therefore thought that bifilms play a major role in influencing the variability of mechanical properties in $\mathrm{Al}$ and $\mathrm{Mg}$ alloys [2].

Dispinar and Campbell [3] used a reduced pressure test (RPT) to expand the internal atmosphere of bifilm defects 
(1)

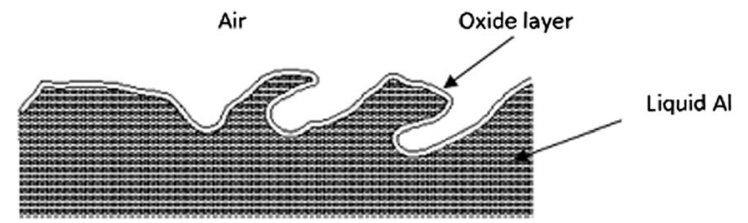

(2)

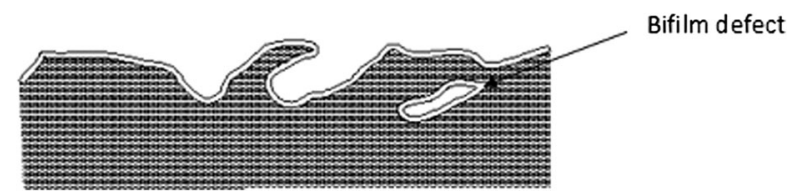

Fig. 1 Sketch of the formation of an entrained double oxide film defect

during solidification of Al-7Si-0.4 Mg alloy. The authors compared two castings (with different amounts of bifilms introduced by different pouring techniques) that were solidified under different reduced pressures and then examined using $\mathrm{x}$-ray radiography. It was noticed that when following an appropriate casting practice that tended to minimize the possibility of bifilm entrainment, the amount of pores in the casting would be a minimum. In contrast for careless casting procedures that allowed the introduction of double oxide films to the casting, the amount of pores would be much higher. In both cases, lowering the pressure under which the castings were solidified resulted in an enlargement of the pores.

The authors argued that bifilms would work as initiators for the gas porosity in Al castings while the hydrogen acted only as a contributor to the porosity formation process [3]. They suggested that, during solidification, the hydrogen, in excess of the solubility limit, comes out of solution and diffuses into the bifilm gap, expanding it into a pore. Therefore, as more bifilms are incorporated into the melt during pouring and handling, more pores would be expected in the solidified casting. The application of vacuum during solidification helped the pores to expand further becoming more visible in the x-ray image. However, in this study, the authors did not present an evidence to support their suggestion that all the pores observed came from oxide films.

Recent researches by Griffiths and Raiszadeh [4], El-Sayed et al. [5-7], and El-Sayed and Griffiths [8] have suggested that $\mathrm{H}$ dissolved in an $\mathrm{Al}$ melt could diffuse into its entrained bifilms, increasing their size and forming oxide-related hydrogen containing porosity, which was found to decrease the Weibull moduli of the tensile properties of castings [8].

The aim of this work was to study the effect the solidification of $\mathrm{Al}$ melt under vacuum on entrained bifilms and to examine the role played by such defects in initiating porosity in $\mathrm{Al}$ casting. The research would allow a more detailed understanding of the behaviour of bifilm defects in commercial alloys and might point towards methods of eliminating the defects once they are formed.

\section{Experimental work}

In order to determine the effect of holding an $\mathrm{Al}$ alloy melt under a vacuum on the entrained bifilm inclusions, about $6 \mathrm{~kg}$ of A356 alloy, with a chemical composition given in Table 1, was melted in an induction furnace. The liquid metal was then stirred in an induction furnace (using a power setting of $7.5 \mathrm{~kW}$ and frequency of $2350 \mathrm{~Hz}$, for $1 \mathrm{~min}$ ) to create new oxide films and introduce them into the melt, which might already contain some old oxide films from the charge material.

The crucible containing the melt was then placed in the vacuum chamber which had been initially preheated to $800{ }^{\circ} \mathrm{C}$, and the chamber internal pressure decreased to 0.2 bar. Subsequently, the heaters of the chamber were turned off to allow the melt to solidify to the room temperature under the reduced pressure. Finally, the chamber was returned to atmospheric pressure and the solidified ingot removed, cut into two halves and the pores on the machined surface of each half investigated using SEM.

\section{Results}

Holding the melt under vacuum would be expected to cause the expansion of any atmosphere within the entrained bifilms. In this experiment, the holding process was interrupted and the liquid metal was allowed to solidify under vacuum in order to determine the nature of the porosity inside the casting.

Figure 2a shows a pore, with an average diameter of $1.5 \mathrm{~mm}$, on the machined surface of one half of the casting. Another pore was found at the same location on the surface of the other half of the casting, which is shown in Fig. 2b. Figure 3a-d shows the results of the energy dispersive $\mathrm{x}$-ray (EDX) analysis that revealed the presence of oxide inside the pores and confirmed its identity as $\mathrm{MgAl}_{2} \mathrm{O}_{4}$ spinel.

Table 1 Chemical composition of A356 alloy

\begin{tabular}{lccccc}
\hline Element & $\mathrm{Si}$ & $\mathrm{Fe}$ & $\mathrm{Cu}$ & $\mathrm{Mg}$ & $\mathrm{Al}$ \\
\hline Percentage & 7.1 & 0.07 & 0.15 & 0.4 & Bal. \\
\hline
\end{tabular}


Fig. 2 Two pores found at symmetrical locations on the two opposite sides of the casting
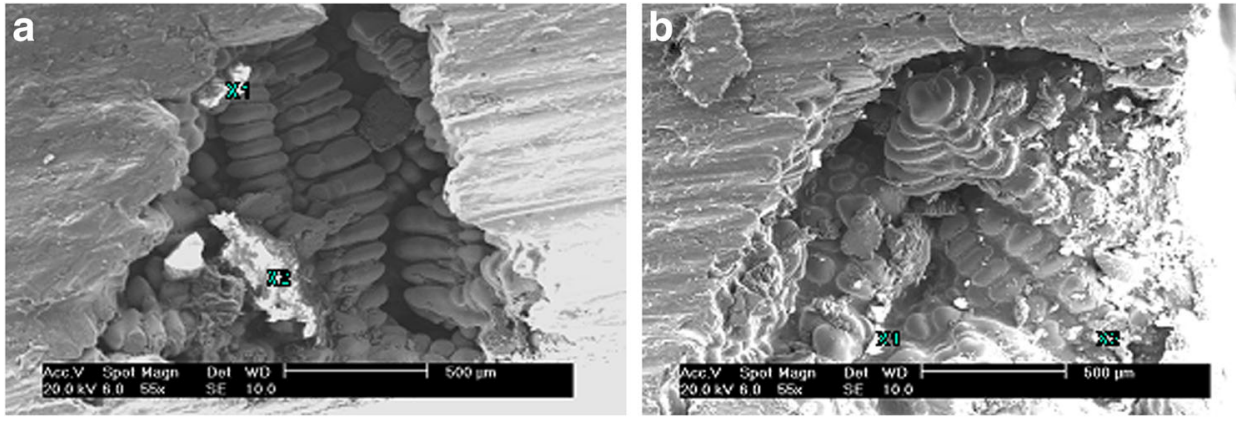

Another example of a pore containing fragments of oxides that was found lying upon the dendrite tips has been illustrated in Fig. 4a, confirmed to be oxide by EDX analysis, as shown in the corresponding EDX spectrum. Figure $4 \mathrm{~b}$ shows a SEM image of an oxide film that was found to cover almost all the entire surface of a pore supporting the suggestion that porosity would be formed by expansion of double oxide film defects. It should be noted that the presence of a relatively thick oxide layer inside a pore, such as in Fig. 4a, could be suggestive of the presence of an old bifilm defect coming from the material charge rather than a new bifilm entrained during the stirring

a

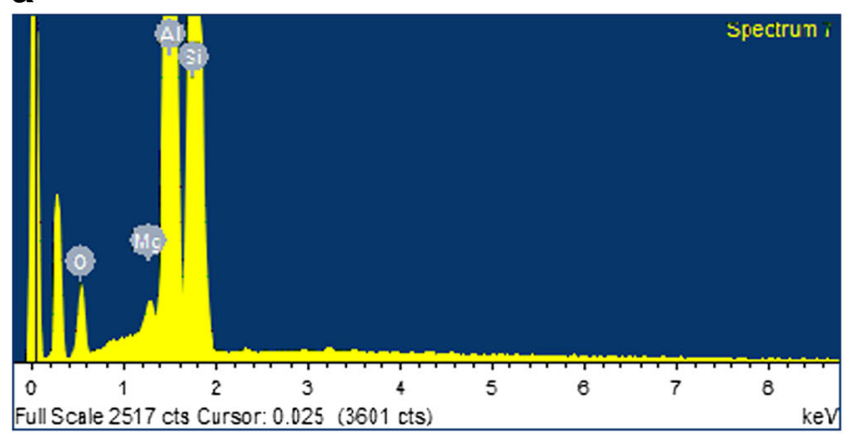

C

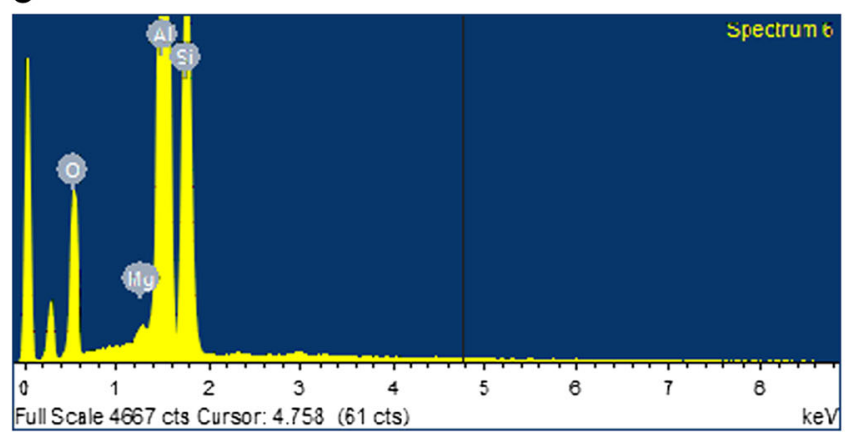

action. The thickness of the oxide film may perhaps be an indication that it had relatively long time to absorb some $\mathrm{Mg}$ into its structure by diffusion. This was also suggested by the relatively stronger $\mathrm{Mg}$ peak in the corresponding EDX spectrum.

For most of the pores analysed, a single oxide film was detected inside each pore, as shown in Fig. 4. However, in a few cases, many oxide fragments were found dispersed over the inside of the pore, as shown in Fig. 5a. Figure 5b, c, shows the EDX analysis of the oxide fragments detected inside the pore. This could be a suggestion of a bifilm that was expanded

\section{b}

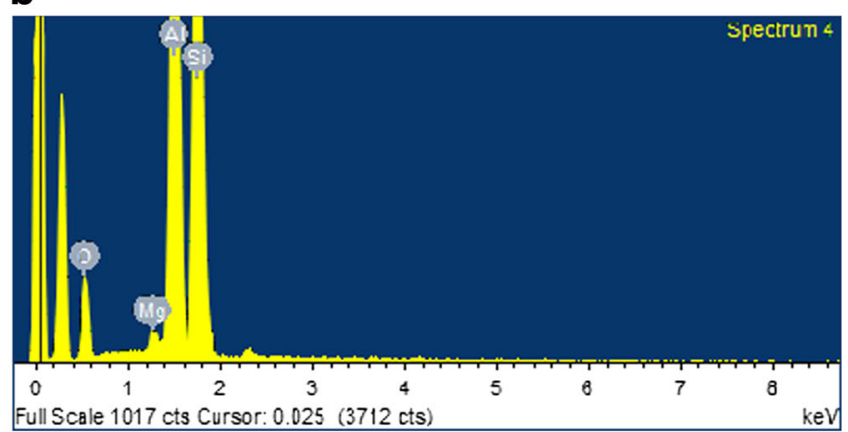

d

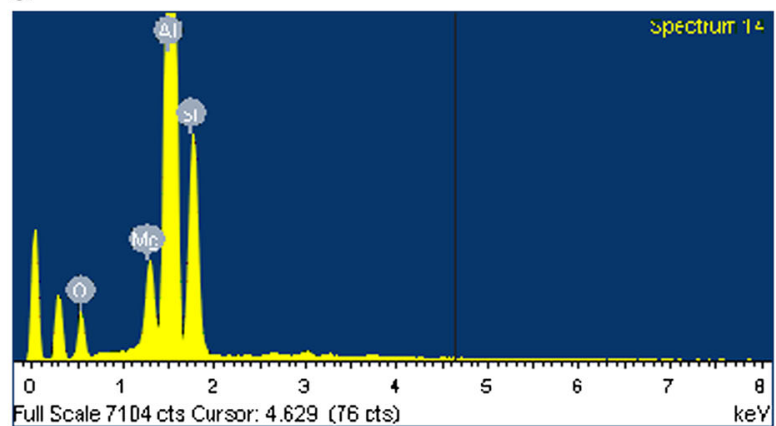

Fig. 3 a, b EDX spectra of the fragments shown in Fig. 2a at locations $X 1$ and $X 2$, respectively. c, $\mathbf{d}$ EDX spectra of the fragments shown in Fig. $2 \mathrm{~b}$ at locations $X 1$ and $X 2$, respectively 

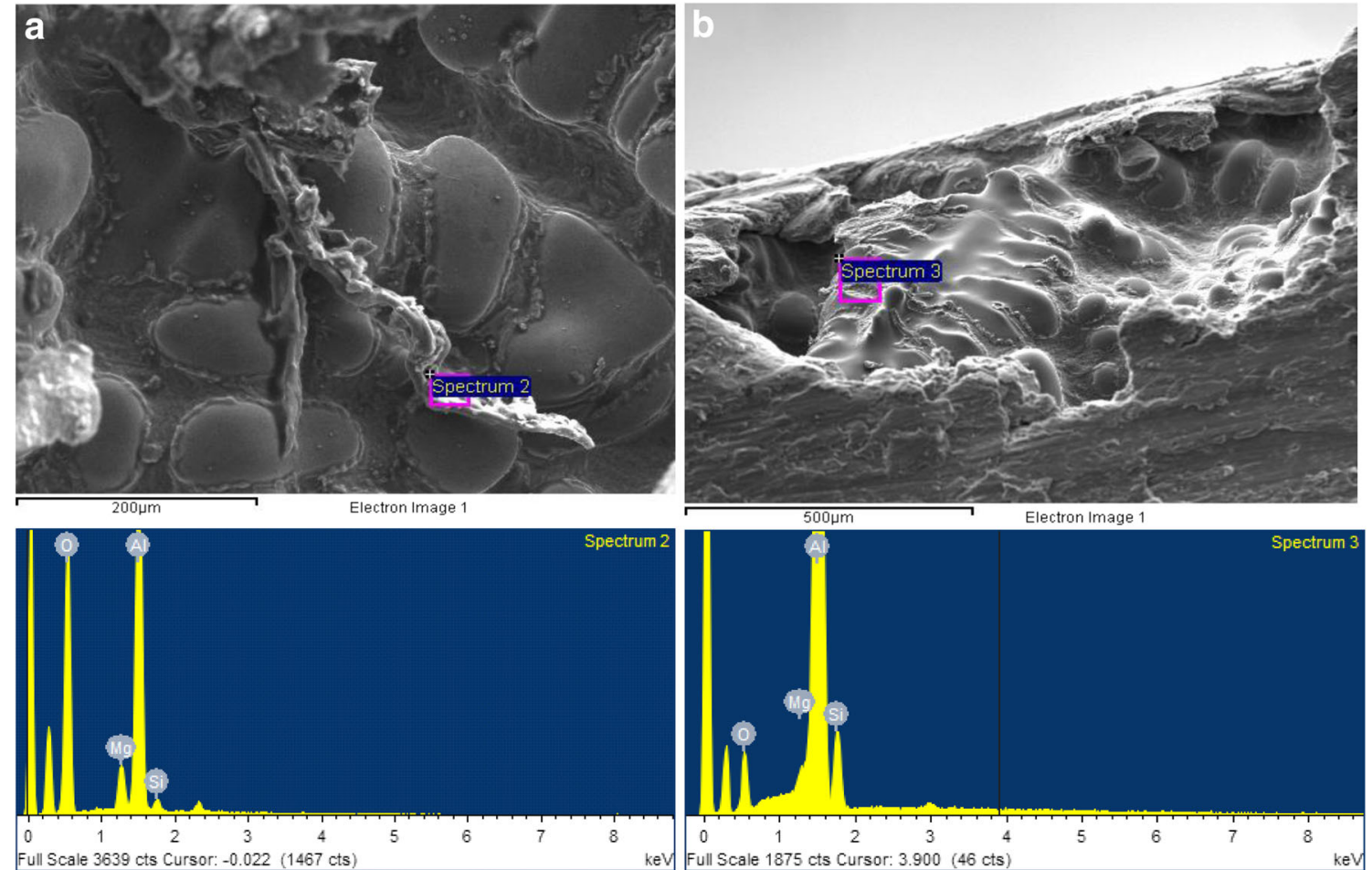

Fig. 4 SEM images with the corresponding EDX analysis of spinel inside pores on the machined surfaces of a casting of A356 Al alloy solidified under vacuum

and then torn apart leaving such oxide fragments within the pore.

Figure 6 shows SEM images for two pores on the machined surfaces of the casting. No oxides were visible on the internal surface of the pore, and the EDX spectrum taken at different locations within the pore did not reveal any oxygen peaks, suggesting this pore may not have originated from an inflated bifilm. Investigation of porosity in this experiment confirmed a relationship for most, but perhaps not all, pores with oxides. This suggests that a possible cause for the formation of porosity in this $\mathrm{Al}$ alloy casting was bifilm defects that were expanded due to the application of vacuum during solidification.

\section{Discussion}

It was suggested by Fox and Campbell [9] and Dispinar and Campbell [3] that placing liquid metal under vacuum may cause its entrained bifilms to expand to form pores. In both works, the authors presented x-ray images of the solidified castings that showed a significant increase in the size of porosity associated with the reduction in the pressure. However, no EDX analysis was carried out inside these pores to verify this hypothesis.

SEM images (presented in Figs. 2, 4, and 5) showed many fragments of oxides inside pores in the casting solidified under vacuum, which were confirmed by EDX analysis to be $\mathrm{MgAl}_{2} \mathrm{O}_{4}$. This suggests that the observed pores were initially bifilm defects that expanded due to the application of a vacuum and the decreased melt pressure around them, which might result in tearing the films apart.

If the liquid aluminium was held under vacuum for a sufficient time, this might allow double oxide film defects to expand and float to the melt surface $[10,11]$. In the experiment performed here, the holding treatment was suspended at an intermediate stage to trap some pores during their presumed journey to the surface of the melt, which were subsequently analysed for evidence of oxide films.

However, SEM images (presented in Fig. 6) also showed a pore that did not reveal oxygen by EDX analysis and therefore may not contain any oxides. This could be because a bifilm that was also expanded under vacuum to form a pore. This pore was then torn open under the reduced pressure around it allowing fresh melt 
Fig. 5 a An SEM image of oxide fragments within a pore on the machined surface of a casting of A356 Al alloy solidified under vacuum. b, c EDX analysis at locations $X 1$ and $X 2$, respectively a

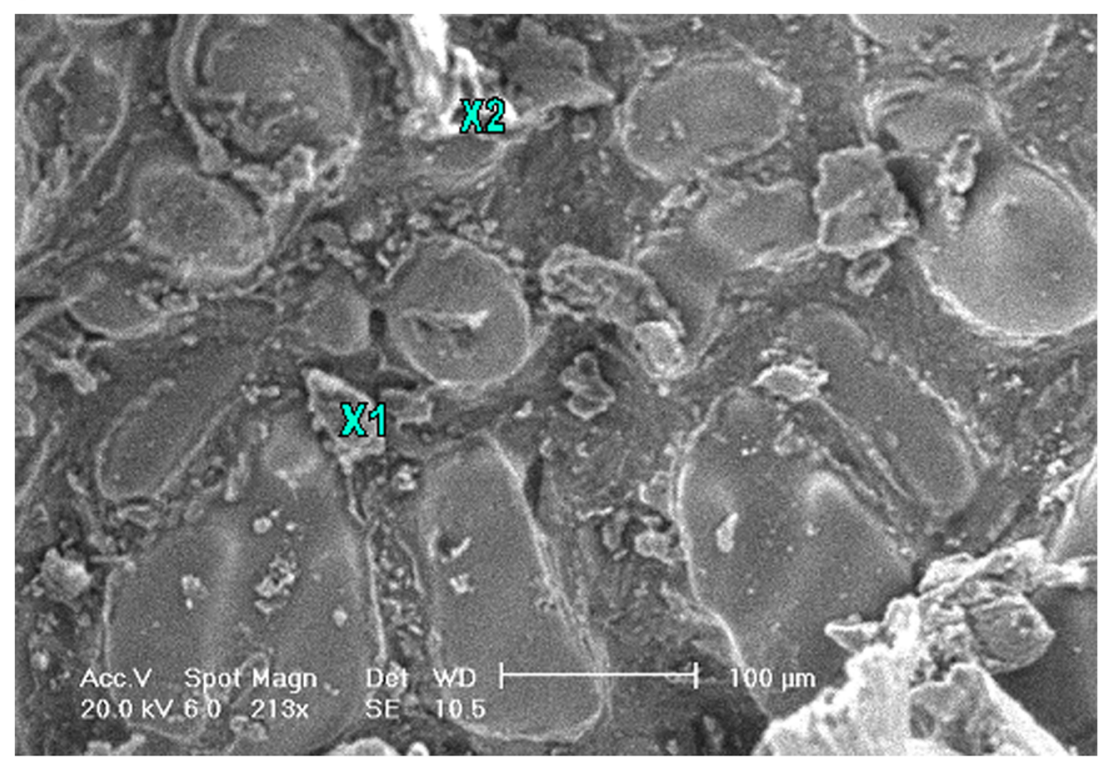

b

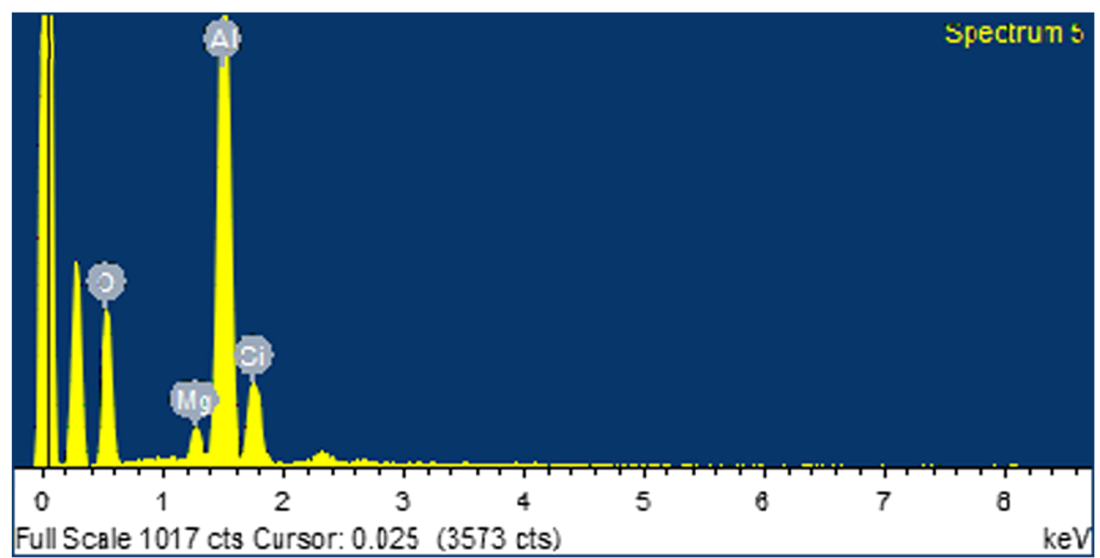

C

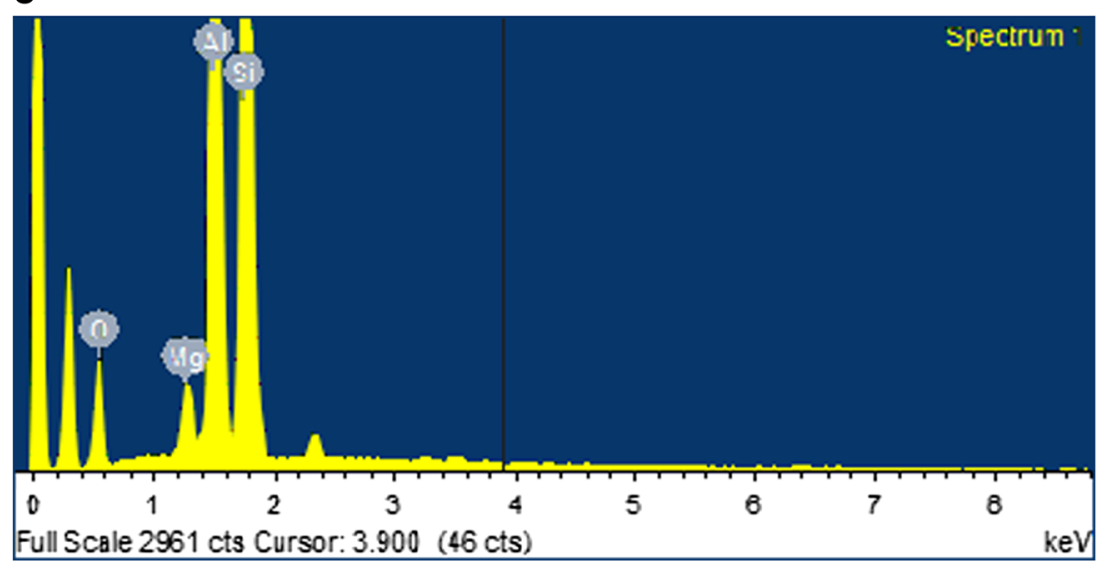

to seal its entire atmosphere and reform a thin oxide layer (about $20 \mathrm{~nm}$ ), which was undetectable by EDX analysis.
The significance of this experiment was that since most of the pores were confirmed to be originated from bifilm defects, 
Fig. 6 a An SEM image of a pore on the machined surface of a casting of A356 Al alloy solidified under vacuum, $\mathbf{b}$ and $\mathbf{c}$ EDX analysis at locations shown in a (named spectrum 2 and spectrum 1 , respectively)

\section{a}

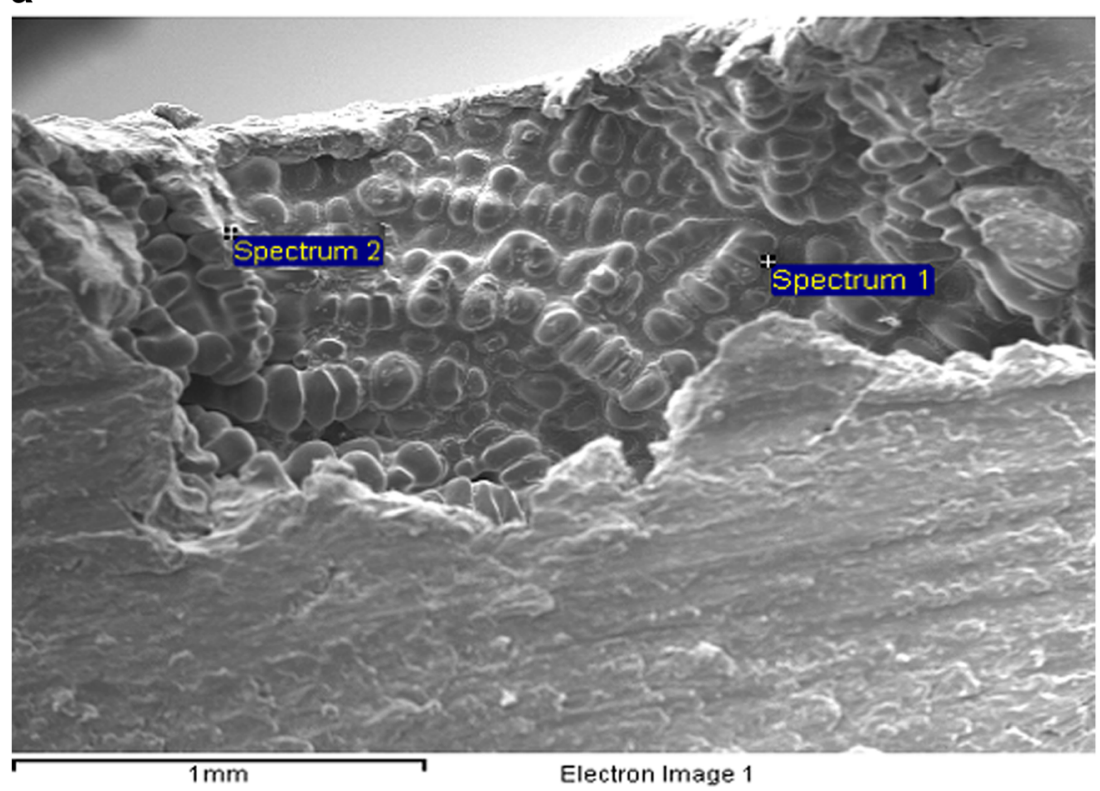

\section{b}

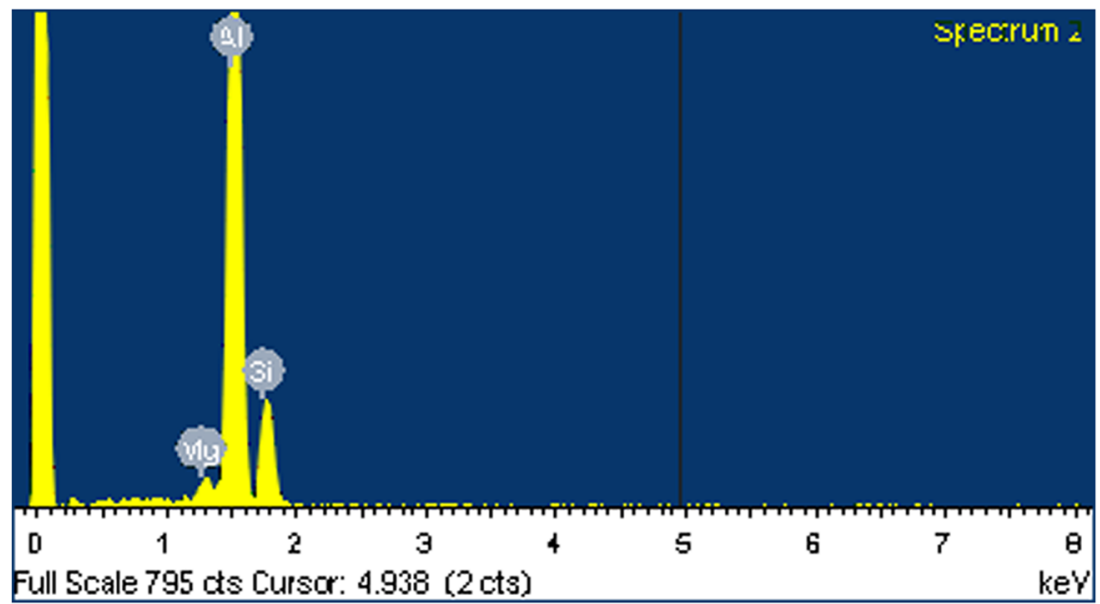

c

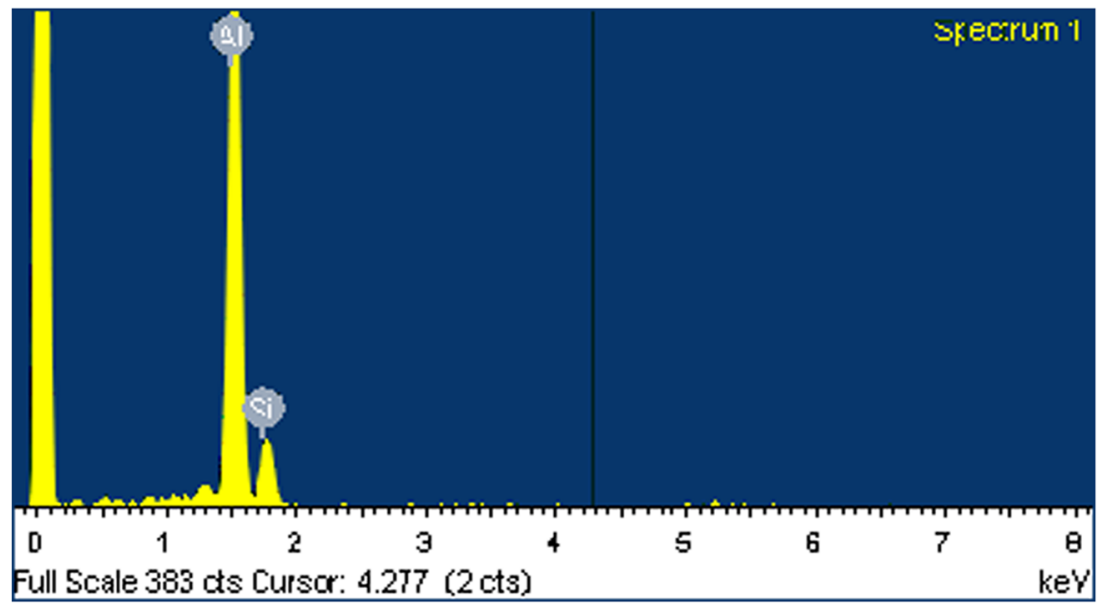


it is rational to suggest that following proper casting practice (intended to minimize melt surface turbulence during mould filling) would lead to the elimination of bifilm entrainment and associated porosity formation. Doing this would allow Al casting producers to obtain substantially defect-free castings at reasonable cost that might be more reliable than many aerospace forgings.

\section{Conclusions}

1. SEM investigation detected many spinel fragments inside porosity in the casting solidified under vacuum, suggesting that such pores were initially bifilm defects that expanded due to the application of the vacuum and then torn apart leaving only some oxide bits within the pores.

2. Entrained bifilms not only can cause premature failure by acting as cracks in the Al casting but also have been associated with other defects, such as hydrogen porosity.

Open Access This article is distributed under the terms of the Creative Commons Attribution 4.0 International License (http:// creativecommons.org/licenses/by/4.0/), which permits unrestricted use, distribution, and reproduction in any medium, provided you give appropriate credit to the original author(s) and the source, provide a link to the Creative Commons license, and indicate if changes were made.

\section{References}

1. Campbell J (2003) Castings, 2nd edn. Butterworth-Heinemann, London

2. Campbell J (2006) Entrainment defects. Mater Sci Technol Ser 22: 127-145

3. Dispinar D, Campbell J (2004) Critical assessment of reduced pressure test. Part 1: porosity phenomena. Int J Cast Metal Res 17:280 286

4. Griffiths WD, Raiszadeh R (2009) Hydrogen, porosity and oxide film defects in liquid Al. J Mater Sci 44(13):3402-3407

5. El-Sayed MA, Salem H, Kandeil A, Griffiths WD (2013) A study of the behaviour of double oxide films in $\mathrm{Al}$ alloy melts. Mater Sci Forum 765:260-265

6. El-Sayed MA, Salem H, Kandeil A, Griffiths WD (2014) Determination of the lifetime of a double-oxide film in Al castings. Metall Mater Trans B 45(4):1398-1406

7. El-Sayed MA, Salem H, Kandeil A, Griffiths WD (2011) Effect of holding time before solidification on double-oxide film defects and mechanical properties of aluminum alloys. Metall Mater Trans B 42(6):1104-1109

8. El-Sayed MA, Griffiths WD (2014) Hydrogen, bifilms and mechanical properties of $\mathrm{Al}$ castings. Int J Cast Metal Res 27(5): 282-287

9. Fox S, Campbel J (2000) Visualisation of oxide film defects during solidification of aluminium alloys. Scr Mater 43:881-886

10. Raiszadeh R, Griffiths WD (2010) The behaviour of double oxide film defects in liquid Al alloys under atmospheric and reduced pressures. J Alloy Compd 491(1-2):575-580

11. El-Sayed MA, Hassanin H, Essa K (2015) Effect of casting practice on the reliability of Al cast alloys. Int J Cast Metal Res 